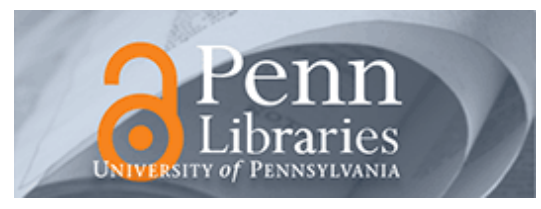

University of Pennsylvania

ScholarlyCommons

Operations, Information and Decisions Papers

Wharton Faculty Research

6-1997

\title{
Does Disputing Through Agents Enhance Cooperation? Experimental Evidence
}

Rachel Croson

University of Pennsylvania

Robert. H. Mnookin

Follow this and additional works at: https://repository.upenn.edu/oid_papers

Part of the Other Economics Commons

Recommended Citation

Croson, R., \& Mnookin, R. H. (1997). Does Disputing Through Agents Enhance Cooperation? Experimental Evidence. The Journal of Legal Studies, 26 (2), 331-345. http://dx.doi.org/10.1086/467998

This paper is posted at ScholarlyCommons. https://repository.upenn.edu/oid_papers/248

For more information, please contact repository@pobox.upenn.edu. 


\title{
Does Disputing Through Agents Enhance Cooperation? Experimental Evidence
}

\author{
Abstract \\ A distinctive characteristic of our mechanisms for conflict resolution is that litigation is carried out by \\ agents chosen by disputing principals. Does the fact that clients choose lawyers to carry on their disputes \\ facilitate dispute resolution or instead exacerbate conflict? The dominant contemporary view is that the \\ involvement of lawyers magnifies the contentiousness of litigation and wastes social resources, \\ prolonging and escalating the conflict in ways that enrich the legal profession but not the clients. But in a \\ recent article, Ronald Gilson and Robert Mnookin suggest another possibility: by choosing lawyers with \\ reputations for cooperation, clients may commit to cooperative litigation in circumstances where the \\ clients themselves would not otherwise trust each other. Using the methodology of experimental \\ economics, this article presents a test of their idea that, by choosing cooperative agents under well- \\ specified procedures, principals may sustain more cooperation than they could on their own. Our \\ experimental findings are consistent with the Gilson-Mnookin hypothesis. \\ Disciplines \\ Other Economics
}


Does Disputing Through Agents Enhance Cooperation? Experimental Evidence Author(s): Rachel Croson and Robert H. Mnookin

Source: The Journal of Legal Studies, Vol. 26, No. 2 (June 1997), pp. 331-345

Published by: The University of Chicago Press for The University of Chicago Law School Stable URL: http://www.jstor.org/stable/10.1086/467998

Accessed: 27-06-2016 20:14 UTC

Your use of the JSTOR archive indicates your acceptance of the Terms \& Conditions of Use, available at

http://about.jstor.org/terms

JSTOR is a not-for-profit service that helps scholars, researchers, and students discover, use, and build upon a wide range of content in a trusted digital archive. We use information technology and tools to increase productivity and facilitate new forms of scholarship. For more information about JSTOR, please contact support@jstor.org.

The University of Chicago Press, The University of Chicago Law School are collaborating with JSTOR to digitize, preserve and extend access to The Journal of Legal Studies 


\title{
DOES DISPUTING THROUGH AGENTS ENHANCE COOPERATION? EXPERIMENTAL EVIDENCE
}

\author{
RACHEL CROSON and ROBERT H. MNOOKIN*
}

\begin{abstract}
A distinctive characteristic of our mechanisms for conflict resolution is that litigation is carried out by agents chosen by disputing principals. Does the fact that clients choose lawyers to carry on their disputes facilitate dispute resolution or instead exacerbate conflict? The dominant contemporary view is that the involvement of lawyers magnifies the contentiousness of litigation and wastes social resources, prolonging and escalating the conflict in ways that enrich the legal profession but not the clients. But in a recent article, Ronald Gilson and Robert Mnookin suggest another possibility: by choosing lawyers with reputations for cooperation, clients may commit to cooperative litigation in circumstances where the clients themselves would not otherwise trust each other. Using the methodology of experimental economics, this article presents a test of their idea that, by choosing cooperative agents under well-specified procedures, principals may sustain more cooperation than they could on their own. Our experimental findings are consistent with the GilsonMnookin hypothesis.
\end{abstract}

\section{INTRODUCTION}

A distinctive characteristic of our formal mechanisms for conflict resolution is that litigation is carried out by agents chosen by the disputing principals. Does the fact that clients choose lawyers to carry on their disputes facilitate dispute resolution or instead exacerbate conflict? The dominant contemporary view is that the involvement of lawyers magnifies the inherent contentiousness of litigation and typically leads to wasting social resources by prolonging and escalating the conflict in ways that may enrich the legal profession but not the clients. ${ }^{1}$ But in a recent article, Ronald Gil-

* Rachel Croson is an assistant professor at the Wharton School of the University of Pennsylvania, and Robert H. Mnookin is the Williston Professor of Law at Harvard Law School, where he is the chair of the Program on Negotiation. This research was supported by the Harvard Negotiation Research Project, as well as by the partial support Mnookin received from the Harvard Law School Program in Law and Economics as a Sheldon Seevak Fellow.

${ }^{1}$ For sources criticizing the legal profession for unnecessarily intensifying hostility between disputants, see Ronald J. Gilson and Robert H. Mnookin, Disputing through Agents:

[Journal of Legal Studies, vol. XXVI (June 1997)]

(C) 1997 by The University of Chicago. All rights reserved. 0047-2530/97/2602-0001\$01.50 
son and Robert Mnookin suggested another possibility: by choosing lawyers with reputations for cooperation, clients might be able to commit to cooperative litigation strategies in circumstances where the clients themselves would not otherwise trust each other. ${ }^{2}$ Using the methodology of experimental economics, this article presents the results of our test of their idea that, by choosing agents under well-specified procedures, principals may be able to cooperate more often than they could without such procedures.

The use of experimental economics methods in legal research is a recent but growing practice. Elizabeth Hoffman and Matthew Spitzer provide an experimental test of some implications of the Coase Theorem, and a later paper by the same authors examines the implications of entitlements and rights in that setting. ${ }^{3}$ Hoffman and Spitzer's papers highlight limitations of the Coase Theorem and discuss the implications of those limitations for the law and legal practice. Don Coursey and Linda Stanley provide an experimental test of pretrial bargaining in the shadow of the law. ${ }^{4}$ Their results generally confirm the theoretical predictions previously generated. ${ }^{5}$ More recently, Babcock and coauthors have examined experimentally how selfserving expectations and beliefs affect the frequency of lawsuits. ${ }^{6}$ In the spirit of this previous research, this article reports an experimental test of a legal theory. Excellent reviews of the field of experimental economics can be found in two recent textbooks. ${ }^{7}$

Because our experiments are based on the "litigation game" and "prelitigation game" developed in the Gilson and Mnookin article, these are sum-

Cooperation and Conflict between Lawyers in Litigation, 94 Colum L Rev 509, 510 nn8-10 (1994).

${ }^{2}$ Id.

${ }^{3}$ Elizabeth Hoffman and Matthew Spitzer, The Coase Theorem: Some Experimental Tests, 28 J Law \& Econ 653 (1982); and Elizabeth Hoffman and Matthew Spitzer, Entitlements, Rights, and Fairness: An Experimental Examination of Subject's Concepts of Distributive Justice, 14 J Legal Stud 259 (1985).

${ }^{4}$ Don Coursey and Linda Stanley, Pretrial Bargaining Behavior within the Shadow of the Law, 8 Intl Rev L \& Econ 161 (1988).

${ }^{5}$ Particularly in R. Mnookin and L. Kornhauser, Bargaining in the Shadow of the Law: The Case of Divorce, 88 Yale L J 950 (1979); and Robert Cooter, Stephen Marks, and Robert Mnookin, Bargaining in the Shadow of the Law: A Testable Model of Strategic Behavior 11 J Legal Stud 225 (1982).

${ }^{6}$ Linda Babcock, George Loewenstein, Samuel Issacharoff, and Colin Camerer, SelfServing Assessments of Fairness and Pretrial Bargaining, 22 J Legal Stud 135 (1993); and Linda Babcock, Henry Farber, Cynthia Fobian, and Eldar Shafir, Forming Beliefs about Adjudicated Outcomes: Perceptions of Risk and Reservation Values, 15 Intl J L \& Econ 289 (No 3, 1995).

${ }^{7}$ Douglas Davis and Charles Holt, Experimental Economics (Princeton University Press, 1992); and John Kagel and Alvin Roth eds, The Handbook of Experimental Economics (Princeton University Press, 1995). 
marized in the next section. For the clients themselves, Gilson and Mnookin argue that many disputes pose a Prisoner's Dilemma encapsulated in their finitely repeated litigation game, with an expected equilibrium of "defect/ defect.' In their "'prelitigation game," disputants choose lawyers who have valuable and observable reputations to represent them in the dispute. These choices are revealed, and any client who has chosen a cooperative lawyer and is facing a noncooperative one may change her decision. Under the assumptions of the prelitigation game, because a lawyer's reputation for cooperation serves as a bond to the client's cooperation in the litigation process, Gilson and Mnookin suggest that the equilibrium changes to full cooperation.

Section III describes our experimental implementation of the Gilson/ Mnookin model. The experiment involved two different treatments of a finitely repeated Prisoner's Dilemma game, one with the prelitigation game and one without. We derive the equilibria for our experimental games and discuss some important experimental procedures. Section IV presents the results. We find that significantly more cooperative agents are chosen (and cooperative moves made) in the prelitigation game than in the litigation game. These results are also compared with slightly different earlier Prisoner's Dilemma experiments. Section V is a brief conclusion.

\section{The Gilson/Mnookin Model}

\section{A. The Litigation Game}

Gilson and Mnookin argue that the Prisoner's Dilemma provides a useful heuristic to illuminate a common characteristic of litigation. They argue that, "[i]n many disputes, each litigant may feel compelled to make a contentious move either to exploit, or to avoid exploitation by the other side. Yet, the combination of contentious moves by both results in a less efficient outcome than if the litigants had been able to cooperate.",8

Gilson and Mnookin model this aspect of litigation by describing initially a "litigation game" in which there are two parties and a judge and the dispute concerns the proper division of $\$ 100$ according to some legal standard. Each party has information not known to the other, some favorable and some unfavorable. Before the judge decides the case, there is a one-stage simultaneous disclosure process in which each litigant hands the judge and the other side a sealed envelope containing information. Only two moves are possible. A party can cooperate by voluntarily disclosing to the other side (and to the judge) all material information in her possession or defect,

\footnotetext{
${ }^{8}$ Gilson and Mnookin, at 514 (cited in note 1).
} 
"which involves adversarial use of disclosure process to hide unfavorable information." "9 The consequence of defection is that the other side must spend $\$ 15$ to force disclosure of some but not all of the withheld information. The payoff matrix takes the familiar form of a Prisoner's Dilemma. ${ }^{10}$

Gilson and Mnookin argue that a Prisoner's Dilemma is an appropriate model for much but not all litigation. ${ }^{11}$ They suggest that a single lawsuit can be seen as consisting of a number of strategic encounters and can be thought of as akin to a finite repetition of the Prisoner's Dilemma game. The unique equilibrium of the finitely repeated game involves defection throughout. $^{12}$

\section{B. The Prelitigation Game}

Gilson and Mnookin go on to suggest that introducing lawyers with reputations into the client's Prisoner's Dilemma model of litigation might, under some circumstances, lead to a more efficient outcome by promoting cooperation. They illustrate this possibility by creating a "prelitigation game" in which clients choose lawyers. It is then the lawyers who go on to play the litigation game for the clients.

Among the lawyers whom a client may choose are a class of practitioners "who have reputations for cooperation which assure that, once retained, they will conduct the litigation in a cooperative fashion." ${ }^{13}$ In the prelitigation game, clients must disclose their choice of lawyers, and it is assumed that each side will know prior to the beginning of the litigation game whether the other side has chosen a cooperative lawyer. In the prelitigation game, if one client chooses a cooperative lawyer (known only to cooperate in litigation) and her opponent does not, then only the client originally

${ }^{9}$ Id at $514-15$.

${ }^{10} \mathrm{Id}$ at 515 . If both sides cooperate, the judge splits the $\$ 100$ equally $(\$ 50 / \$ 50)$. If both defect, each party receives $\$ 35$, the same $\$ 50$ in judgment minus $\$ 15$ spent to disclose information. If one player cooperates and the other defects, the judge awards the defector $\$ 70$ and the sucker only $\$ 30$ because not all of the defector's unfavorable information is revealed to the judge. The sucker thus has a net recovery of only $\$ 15$.

${ }_{11}$ We will not repeat here the justifications provided in the article for the use of the Prisoner's Dilemma to model litigation. See id at 516-20, 534-37. Gilson and Mnookin discuss at some length the extent to which the evidence of existing institutional patterns is consistent with the various assumptions underlying the "litigation game" and "prelitigation game."

${ }^{12}$ Id at 520-522. There has been experimental and theoretical work from many different disciplines using the finitely repeated Prisoner's Dilemma game, originally attributed to A. W. Tucker. Similarities between previous experimental research and our results are addressed below.

${ }^{13}$ Id at 522. The article develops in some detail the reasons one might expect there would be a supply of as well as demand for cooperative lawyers (id at 522-27), as well as the various agency problems that might subvert cooperation (id at 527-34). 
choosing a cooperative lawyer can alter her choice of attorney. Thereafter, the litigation game begins, each client being represented by their own lawyer and no further changes in lawyers allowed.

When there are only two types of lawyers to choose between (cooperative and gladiatorial), the prelitigation game has a weakly dominant strategy of always choosing a cooperative lawyer. By choosing cooperative attorneys who will not defect in the litigation game-because doing so will destroy their valued reputation-clients are able to avoid the inefficient outcome of what would otherwise be a Prisoner's Dilemma.

Another way to understand the result is to see that lawyers, acting as agents, can extend the finitely repeated Prisoner's Dilemma game and thus change the equilibrium. The extension achieved through the prelitigation game relies on the notion of lawyers having reputations for cooperation that are publicly known. ${ }^{14}$

\section{EXPERIMENTAL IMPLEMENTATION}

\section{A. The Games and Equilibria}

The Gilson/Mnookin model predicts that there will be more cooperation in the prelitigation game than in the litigation game. The experiment designed to test this prediction involves two treatments of a finitely repeated Prisoner's Dilemma game.

In both treatments, subjects are shown a standard Prisoner's Dilemma matrix (Figure 1) and asked to choose an agent to play this game 10 times in a row for them (to represent them in a lawsuit). Agent A (the cooperative lawyer) always plays A (the cooperative move) in the matrix below. Agent $\mathrm{B}$ (the gladiator lawyer) always plays B (the noncooperative move) in the matrix below. The experiment used to test this model introduces a third sort

${ }^{14}$ Two other models use the technique of extending a finitely repeated Prisoner's Dilemma game to induce cooperation. David Hirshleifer and Eric Rasmusen (Cooperation in a Repeated Prisoners' Dilemma with Ostracism, 12 J Econ Behav \& Org 87 (1989)) present a model of an $n$-person finitely repeated Prisoner's Dilemma with ostracism (banishment) in which cooperation is sustainable. This model has some similarities to the lawyer's viewpoint in the prelitigation game described in Gilson and Mnookin (cited in note 1). There, noncooperative lawyers are not hired (and are thus effectively ostracized), sustaining the population of cooperative lawyers. In a different extension Robert Lapson (Cooperation by Indirect Revelation through Strategic Behavior, 23 Intl J Game Theory 65 (1994)) extends the one-stage Prisoner's Dilemma game to a two-stage game to induce cooperation. Two distinctions between this extension and that of Gilson and Mnookin are worth noting. First, Lapson's model takes a single-shot game and extends it to a two-stage single-shot game, while Gilson and Mnookin take a finitely repeated game and extend it an additional stage. Second, Lapson's extension occurs at the end of the Prisoner's Dilemma game, while Gilson and Mnookin's is at the beginning. 


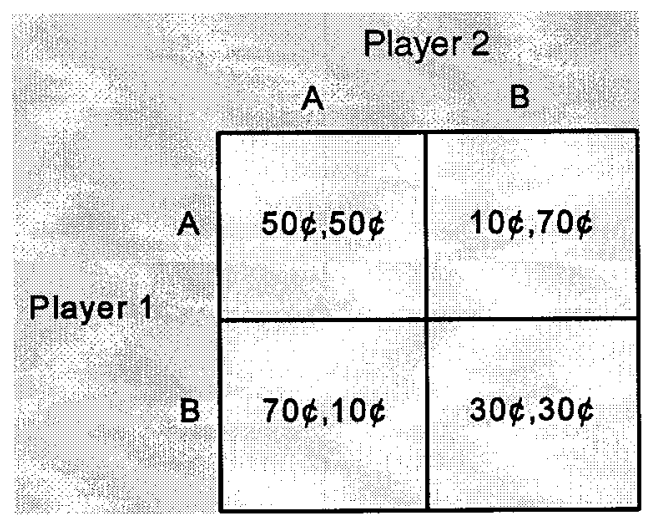

Figure 1.-The Prisoner's Dilemma matrix

of lawyer, who is a mix between the two; the gladiator lawyer remains weakly dominant. Agent $\mathrm{C}$ (the lawyer without a reputation) will play any prespecified combination of $A$ and $B$ in periods $1-10$. For simplicity, agent C's choices are assumed to be strict mixtures of moves A and B (subjects choosing agent $\mathrm{C}$ and specifying all $\mathrm{A}$ moves are treated as having chosen agent $\mathrm{A}$ ).

In the treatment without the prelitigation game, subjects choose lawyers who then go on to represent them. In this game, the dominant strategy equilibrium is to choose a gladiator lawyer (agent B). ${ }^{15}$

In the prelitigation game treatment, subjects choose a lawyer and are then matched. Any subject who chooses a cooperative lawyer (agent A) and faces a lawyer who is not cooperative (agents B or C) is given the option to change his choice. This two-stage game is depicted in Figure 2. The single numbers in the matrix of Figure 2 refer to the trees in the bottom part of the figure. Notice that the payoffs when one player chooses agent $\mathrm{C}$ are described as ranges rather than values. The exact value will depend on what

15 Assume your counterpart chooses agent A. If you choose agent A you will earn $\$ 5$ in the upcoming game. If you choose agent B you will earn $\$ 7$ in the upcoming game. If you choose agent $\mathrm{C}$ you will earn somewhere strictly between $\$ 5$ and $\$ 7$ in the upcoming game (depending on exactly what mix of moves you use). Since you earn at least as much by choosing agent $\mathrm{B}$ as by choosing any other agent, agent $\mathrm{B}$ is your best response in this case. Now assume your counterpart chooses agent B. Choosing agent A earns you \$1, while choosing agent $\mathrm{B}$ earns you $\$ 3$. Again, agent $\mathrm{C}$ earns you some amount between $\$ 1$ and $\$ 3$. Your best response is to choose agent $\mathrm{B}$ in this case as well. Agent $\mathrm{C}$ is a combination of agents $\mathrm{A}$ and $\mathrm{B}$; thus agent $\mathrm{B}$ is also a best response when your counterpart chooses agent C. Since agent $\mathrm{B}$ is your best response no matter what your counterpart chooses in the upcoming game, agent B is a dominant strategy. Having both players choose agent B is the unique equilibrium of this game. 

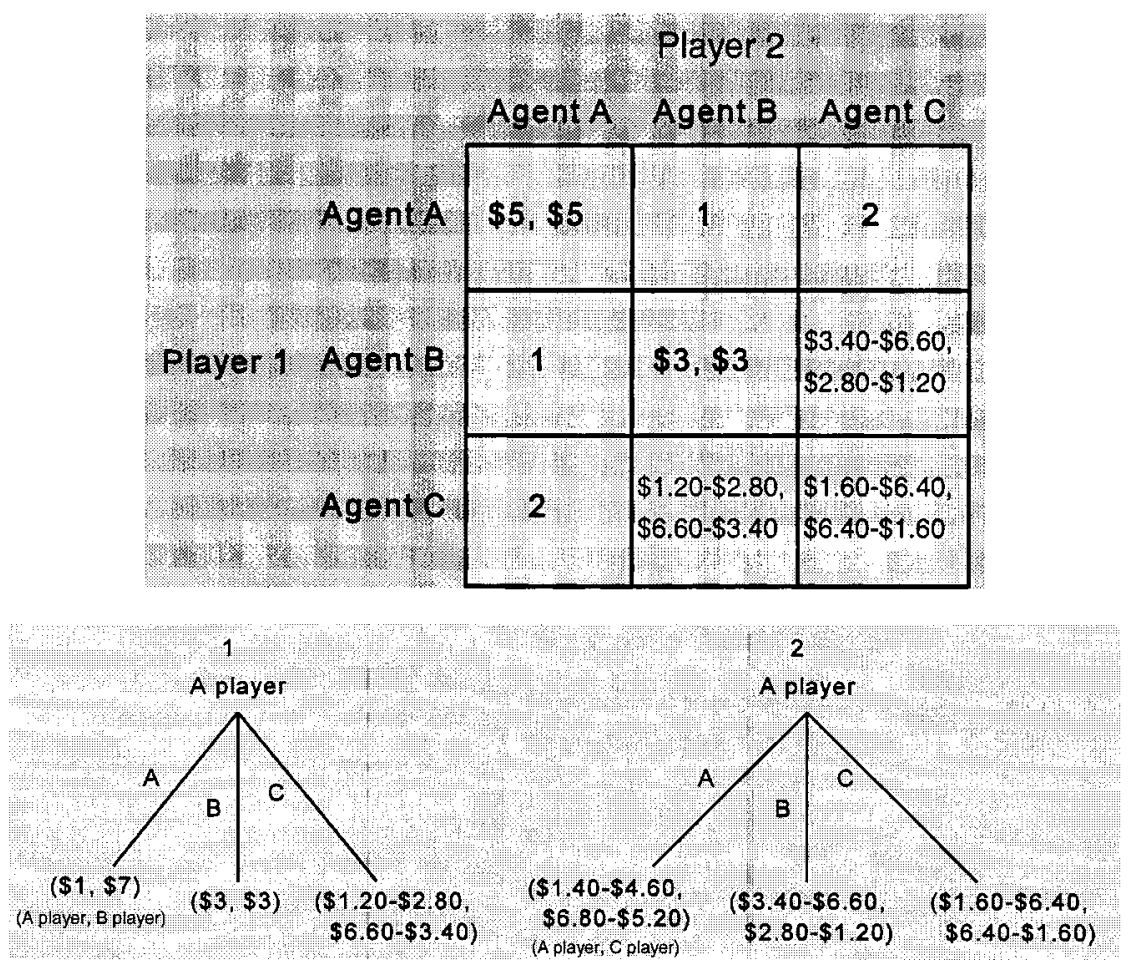

Figure 2.-The prelitigation game

mixture the subject chooses. ${ }^{16}$ This game has a Pareto-optimal subgameperfect Nash equilibrium of always choosing agent A (cooperate throughout). In this equilibrium both players choose agent A (neither has the opportunity to switch), and both earn $\$ 5$. To see that this is an equilibrium we show no player can be made better off by playing some other move. ${ }^{17}$ This

${ }^{16}$ For example, assume one player chooses agent B while the other chooses agent $\mathrm{C}$. How much could each of them earn? If the agent $C$ player specifies the most cooperative moves possible (nine A moves and one B move), she will earn $\$ 1.20$, while the agent B player will earn $\$ 6.60$. If the agent $C$ player specifies the least cooperative moves possible (nine $\mathrm{B}$ moves and one A move), she will earn $\$ 2.80$, while the agent B player will earn $\$ 3.40$. As the agent $\mathrm{C}$ player moves from more cooperative moves to less cooperative moves, her payoff rises while agent B's payoff falls. Other ranges of payoffs in this and future figures were constructed in a similar manner. Strictly speaking, a matrix that completely described this game would include agents $c_{1}, c_{2}, \ldots, c_{\mathrm{n}}$, where $n$ is the total number of possible combinations of moves A or B over 10 periods. However, all these moves will be dominated, thus for expositional simplicity we here combine those strategies into a single one, $\mathrm{C}$.

${ }^{17}$ Consider a player choosing agent B instead. We go to tree 1 and see that the A player (his counterpart) will have an opportunity to change his agent. If he keeps his choice at agent 


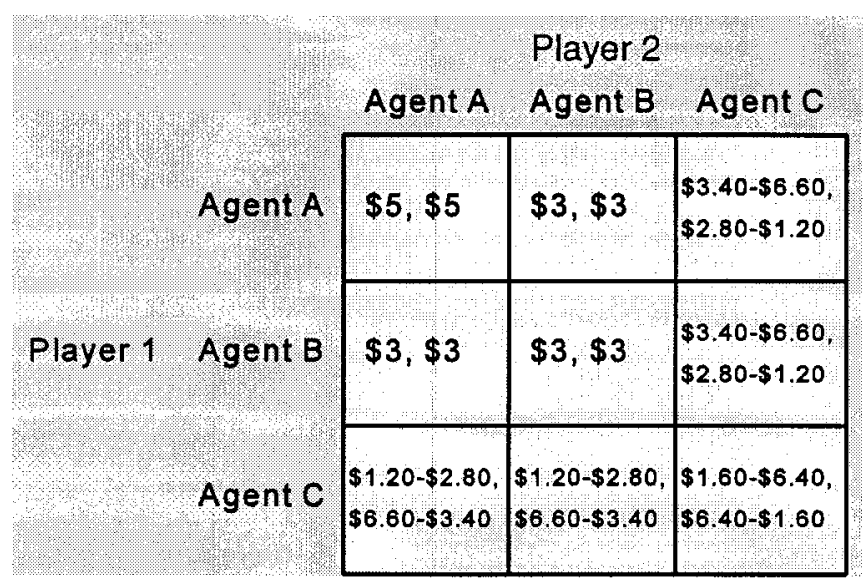

FIGURE 3.- Reduced-form matrix

game also has a (weak) Nash equilibrium of always choosing agent B. To see that this is also an equilibrium we refer to Figure 3. The payoffs in Figure 3 were calculated by assuming the A player chooses the profit-maximizing option, then by folding back the trees in Figure 2 and placing the end payoffs into the original matrix.

Both players choosing agent $\mathrm{A}$ in the matrix above is a Nash equilibrium of this game, as shown in note 16 above. However, both players choosing agent $\mathrm{B}$ is also an equilibrium. If both players do it, neither has any incentive to deviate. ${ }^{18}$ This equilibrium is less attractive than the agent A equilib-

$\mathrm{A}$, he will earn $\$ 1$. If he changes his choice to agent $\mathrm{B}$, he will earn $\$ 3$. If he changes his choice to agent $C$, he will earn anywhere between $\$ 1.20$ and $\$ 2.80$, depending on what sequence of moves he chooses. Choosing agent $\mathrm{B}$ is his best response. Now both players are using agent $\mathrm{B}$, so the payoff from this original agent $\mathrm{B}$ choice is $\$ 3$. Choosing agent $\mathrm{A}$ initially earned $\$ 5$, thus, if the other player is choosing agent $\mathrm{A}$, you prefer choosing agent $\mathrm{A}$ to agent $\mathrm{B}$. What about agent $\mathrm{C}$ ? Consider a player choosing agent $\mathrm{C}$ instead of agent $\mathrm{A}$. We go to tree 2 and see that the A player (his counterpart) will again have an opportunity to change his agent. If he keeps his choice at agent $\mathrm{A}$, he will earn anywhere between $\$ 1.40$ and $\$ 4.60$, depending on the particular moves the $\mathrm{C}$ player specified for his agent. If he changes his choice to agent $\mathrm{B}$, he will earn anywhere between $\$ 3.40$ and $\$ 6.60$. If he changes his choice to agent $C$, he will earn anywhere between $\$ 1.60$ and $\$ 6.40$, depending on what sequence of moves he chooses. Again, choosing agent B is his best response. Now the original player is using agent $\mathrm{C}$, and the other player is using agent $\mathrm{B}$. The payoff to the original player from this combination of strategies is anywhere between $\$ 1.20$ and $\$ 2.80$. Choosing agent $\mathrm{A}$ initially earned $\$ 5$, thus, if the other player is choosing agent $\mathrm{A}$, you prefer choosing agent $\mathrm{A}$ to agent $\mathrm{C}$.

${ }^{18}$ Consider a player choosing agent A instead. He will then have an opportunity to change, and his best response implies changing his choice back to agent $\mathrm{B}$. Thus the player is no better off having changed his choice. Consider a player choosing agent $\mathrm{C}$ instead. He will not have an opportunity to change his choice (he has not chosen a cooperative agent); thus 
rium for two reasons. First, it is a Pareto-inferior equilibrium. Second, and most important, it involves playing a weakly dominated strategy (choosing agent B). Thus this equilibrium does not survive any equilibrium refinements (for example, trembling-hand perfection). ${ }^{19}$ Interestingly enough, playing agent $\mathrm{C}$ with any distribution of moves is not an equilibrium. Agent $\mathrm{B}$ strictly dominates agent $\mathrm{C}$.

As one seminar participant pointed out, there is a sense in which the prelitigation game might result in less cooperation than the litigation game. ${ }^{20}$ If we hold initial choices of agents constant, the prelitigation game gives players an opportunity to switch away from their initial choice of agent A, an opportunity they would not have had in the litigation game. If, for example, three out of five players choose agent $\mathrm{A}$ in the litigation game, pairing each player with each other player yields approximately 11 percent $(\mathrm{A}, \mathrm{A})$ pairs, 54 percent $(\mathrm{A}, \mathrm{B})$ pairs, and 35 percent $(\mathrm{B}, \mathrm{B})$ pairs. If players chose the same agents initially in the prelitigation game, and then everyone who had the opportunity to switch actually switched to agent B, the mix would become approximately 11 percent $(\mathrm{A}, \mathrm{A})$ pairs and 89 percent $(\mathrm{B}, \mathrm{B})$ pairs (since all the agent A players previously stuck in the (A, B) pairs would change their representation to agent B). The claim that the prelitigation game implements more rather than less cooperation relies on enough subjects changing their initial choices from agent $\mathrm{B}$ to agent $\mathrm{A}$ in the prelitigation game, as the equilibrium predicts. ${ }^{21}$

As in the Gilson/Mnookin model, the unique Nash equilibrium of the litigation game used in this experiment involves both players choosing a gladiator lawyer (agent B). There are two Nash equilibria of the prelitigation game, both players choosing a cooperative lawyer (agent A) and both choosing a gladiator lawyer (agent B). However, the agent A equilibrium Pareto-dominates the agent $\mathrm{B}$ equilibrium and is the only one which survives equilibrium refinements.

he will earn anywhere between $\$ 1.20$ and $\$ 2.40$, depending on which mixture of A and B moves he specifies. However, this is strictly less than the $\$ 3$ he would have earned had he remained with agent $\mathrm{B}$. Thus if both players choose agent $\mathrm{B}$, neither has an incentive to change his move.

${ }^{19}$ For a description of trembling-hand perfection and other equilibrium refinements, see Drew Fudenberg and Jean Tirole, Game Theory (MIT Press, 1991).

${ }^{20}$ We thank Brian Lambert for bringing this point to our attention. The following analysis ignores possible choices of agent $\mathrm{C}$ altogether.

${ }^{21}$ If the prelitigation game involves only slightly more players choosing agent $\mathrm{A}$ than the litigation game, the end result will be more defection rather than less. Brian Lambert (personal communication) suggests that, as the percentage of B players grows, the costs of allowing A players to switch in round 2 may overcome the benefits of the model's incentives to "try A." In particular, if there is a 25 percent B population, then the prelitigation game and the litigation game are almost indistinguishable in their results. 


\section{B. Experimental Implementation}

Subjects in the experiment were all students at Harvard Law School. Subjects were recruited in their classrooms, and the experiment took place in the same rooms. Forty subjects participated in the litigation game (baseline) treatment, and 46 in the prelitigation game treatment.

Copies of the instructions were distributed to the subjects, placed on an overhead projector, and read aloud to ensure common information. Since the game is symmetric, all subjects were told to imagine they were the row player in the game. Each subject chose one of three strategies (attorneys), after which their response forms were collected.

In the baseline treatment, subjects moves were matched up and earnings calculated while they completed a postexperimental questionnaire. Earnings were placed into envelopes, labeled with subject numbers rather than names, which subjects picked up as they left the classroom.

In the prelitigation game treatment subjects were matched up as well. All subjects then received a second sheet of paper. If another move was required of them they responded on the sheet; if not, their sheet simply told them to return it to the monitor. All sheets handed out at this stage were collected, thus no subject could tell whether or if another subject had a secondary move to make. Earnings were then calculated, placed in envelopes and picked up by the subjects as before, after they had completed their postexperimental questionnaire. No show-up fee was paid, although all subjects were paid their earnings in the game.

TABLE 1

RAW RESULTS

\begin{tabular}{lrrr}
\hline \hline & \multicolumn{3}{c}{ AgENT CHOICE } \\
\cline { 2 - 4 } & \multicolumn{1}{|c}{ A } & \multicolumn{1}{c}{ B } & \multicolumn{1}{c}{ C } \\
\hline Litigation game $(N=40)$ & 7 & 17 & 16 \\
Prelitigation game $(N=46)$ & 35 & 6 & 5 \\
\hline
\end{tabular}

\section{Experimental Results}

\section{A. Raw Data and Analysis}

Table 1 summarizes the raw data from the experiment. ${ }^{22}$ The main results from this experiment support the theory offered by Gilson and Mnookin:

${ }^{22}$ Two $\mathrm{C}$ choosers in the normal game chose all one move (one chose all $\mathrm{A}$ and one chose all B). This analysis counts those choices as A or B choices. 
TABLE 2

$\%$ Choices of Cooperative Agent (Agent A)

\begin{tabular}{lccc}
\hline \hline & Percentage & $\begin{array}{c}t \text {-Test } \\
\text { of Proportions }\end{array}$ & $\begin{array}{c}\text { Significance } \\
\text { Level }\end{array}$ \\
\hline Litigation game $(N=40)$ & 17.5 & 6.738 & .000 \\
Prelitigation game $(N=46)$ & 76.1 & & \\
\hline
\end{tabular}

TABLE 3

$\%$ Cooperative Moves Made (A)

\begin{tabular}{lccc}
\hline \hline & Percentage & $\begin{array}{c}t \text {-Test } \\
\text { of Proportions }\end{array}$ & $\begin{array}{c}\text { Significance } \\
\text { Level }\end{array}$ \\
\hline Litigation game $(N=400)$ & 39.0 & 13.522 & .000 \\
Prelitigation game $(N=460)$ & 80.4 & & \\
\hline
\end{tabular}

significantly more cooperative agents are chosen in the prelitigation game than in the litigation game. Table 2 shows the percentage of cooperative agents chosen in each treatment and reports the significance test. ${ }^{23}$

Another measure that may be of interest is the number of cooperative moves made by the subjects. This differs from the choice of cooperative agents only in that some individuals chose agent $\mathrm{C}$, whose actions included some mix of cooperative and noncooperative moves. The two treatments were significantly different in the expected direction for this measure of cooperativeness as well, as shown in Table $3 .^{24}$

One final question that the data can address involves changes in the type of lawyer actually made in the prelitigation game. As was seen in Figure 2, if a player is given an opportunity to change his choice, his dominant strategy is to change to agent $\mathrm{B}$. In the prelitigation game treatment of the ex-

${ }^{23}$ The significance test used here is the $t$-test of proportions. Two proportions are considered different from each other if their $t$-statistic is significant, where $P_{i}$ is the proportion of successes in treatment $i, N_{i}$ is the number of observations, and $t$ is calculated as

$$
\frac{P_{1}-P_{2}}{\sqrt{\frac{P_{1}\left(1-P_{1}\right)}{N_{1}}+\frac{P_{2}\left(1-P_{2}\right)}{N_{2}}}} .
$$

${ }^{24}$ There are some statistical problems with this measure. The $t$-test of proportions assumes independent observations, which is not the case when individual moves are being analyzed (since one subject generates 10 observations). The difference between the treatments is so significant, however, that this technicality is overlooked here. 
periment nine subjects were in a position to change their choices. Of those, six switched to agent $\mathrm{B}$ (the dominant strategy), while three switched to agent $\mathrm{C}$. None remained with agent $A .{ }^{25}$

The results of this experiment strongly supported the predictions of Gilson and Mnookin. As predicted, subjects in the prelitigation game were significantly more likely to choose cooperative lawyers than were subjects in the litigation game.

\section{B. Comparison with Previous Experiments}

The litigation game treatment of this experiment provides an interesting comparison with other repeated Prisoner's Dilemma experiments. ${ }^{26}$ In most previous experiments, subjects are told their counterpart's move, and their earnings, in round $n$ before having to make their decisions in round $n+1$. Thus reactive strategies (like tit-for-tat and trigger strategies) are feasible. In both treatments of this experiment, subjects specified all 10 moves in advance; thus no reactive strategies were permitted. Are the results of this experiment similar to those observed under reactive conditions?

The answer is generally yes, with some caveats. Comparing data across experiments is always a delicate operation. Though all the experiments discussed in this section used a finitely repeated Prisoner's Dilemma, the exact payoffs in each cell varied from experiment to experiment. Experimental procedures (instructions, compensation, anonymity, and the like) all varied as well.

In one of the original Prisoner's Dilemma experimental papers, Lester Lave ran 19 pairs of subjects through a Prisoner's Dilemma 100 times. ${ }^{27}$ The payoffs when both subjects cooperated was positive, although the "sucker" payoff (the payoff a player earns when he cooperates and his counterpart defects) and the payoff to subjects when they both defected were negative. Subjects were paired, given some money, played the game 100 times, and took home their retained earnings. Data from this experi-

${ }^{25}$ Of the three players who switched to $\mathrm{C}$, one chose five A moves and five B moves, one chose four A moves and six B moves, and the last chose six A moves and four B moves.

26 Anatol Rapoport and Albert Chammah's book Prisoner's Dilemma (University of Michigan Press, 1965) provides a historical review of Prisoner's Dilemma experiments in experimental psychology. Robyn Dawes and Richard Thaler provide a more recent discussion of cooperation more generally: Anomalies: Cooperation, 2 J Econ Persp 187 (1988). For a recent review of Prisoner's Dilemma experiments, see David Sally, Conversation and Cooperation in Social Dilemmas: A Meta-analysis of Experiments from 1958-1992, 7 Rationality \& Soc 58 (No 1, 1995).

27 Lester Lave, An Empirical Approach to the Prisoners' Dilemma Game, 76 Q J Econ 424 (1962). 


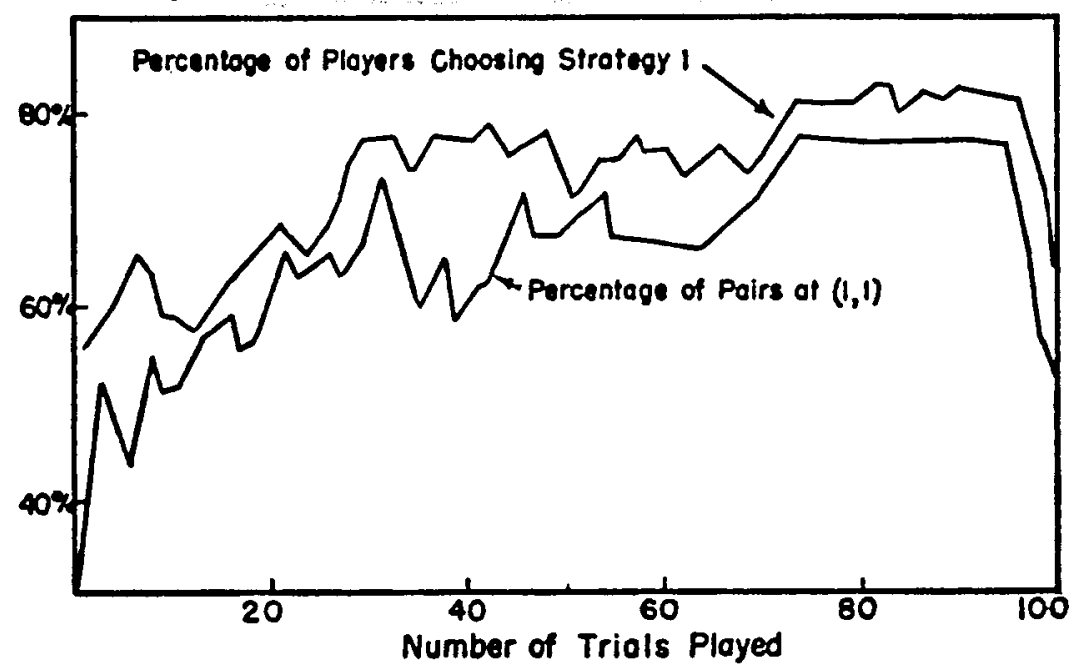

FIGURE 4.-Players cooperating in the Prisoner's Dilemma: first series. (This figure is reproduced from Lester Lave, An Empirical Approach to the Prisoners' Dilemma Game, 76 Q J Econ 424, figure 6 (1962).)

ment are in the form of a graph, reproduced here as Figure 4, which depicts the percentage of cooperative moves for each of the 100 periods.

The percentage of cooperative moves varies over the course of the game, from just under 60 percent in the first period to just above 60 percent in the last. Overall, the level of cooperation is higher than we observed in the litigation game in this article (39 percent).

Anatol Rapoport and Albert Chammah report an experiment in which 70 pairs of subjects were matched and played the Prisoner's Dilemma 300 times. They tested games of varying levels of payoffs, while retaining the Prisoner's Dilemma structure. As in the Lave experiments, payoffs from both players defecting and the sucker's payoff were negative. However, subjects in this experiment did not keep the money they earned in the game but were instead given a flat participation fee. Rapoport and Chammah report cooperation rates varying from 27 percent to 77 percent, based on the particular payoff configuration. ${ }^{28}$

In possibly the most comparable experiment to ours, L. G. Morehous ran (among other games) a 10-round finitely repeated Prisoner's Dilemma experiment. ${ }^{29}$ (The increased comparability comes from the similarities of the

${ }^{28}$ Rapoport and Chammah (cited in note 26).

${ }^{29}$ L. G. Morehous, One-Play, Two-Play, Five-Play and Ten-Play Runs of Prisoner's Dilemma 10, No. 3 Conflict Resolution 354 (1966). 
lengths of the games.) Ninety-six pairs of undergraduate students participated in the experiment. They were paid based on their moves. Again, payoffs to joint defection as well as the sucker's payoff were negative, while payoffs to joint cooperation were positive. Morehous found that 42 percent of subjects made cooperative moves in the 10-period repeated game.

Finally, in a more modern treatment of the finitely repeated Prisoner's Dilemma, James Andreoni and John Miller report an experiment in which 14 subjects play a series of 20 10-round games. ${ }^{30}$ Subjects are paid their earnings, and all payoffs in the matrix are nonnegative. They find that, within each set of 10 games, subjects cooperate substantially more in the early rounds than in the later ones. Average cooperation rates start at just over 60 percent and decrease through the course of the game to end under 10 percent, with the decrease being relatively monotonic. ${ }^{31}$

The experimental results from the litigation game are quite similar to those of previously run 10-round repeated Prisoner's Dilemma games. Our subjects made 39 percent of their moves cooperatively, while Morehous's subjects cooperated 42 percent of the time. Varying levels of cooperation were found by Lave and Rapoport and Chammah when the game was repeated hundreds of times.

\section{Conclusions}

This article presents an experimental test of a Gilson/Mnookin model in which the choice of lawyer facilitates client cooperation in lawsuits. Litigation without lawyers is modeled as a finitely repeated Prisoner's Dilemma. Litigation with lawyers involves a prelitigation game in which, with no risk, a client can initially choose a cooperative lawyer and thus signal a willingness to cooperate. In the Gilson/Mnookin model, the addition of this prelitigation stage changes the equilibrium from defection to cooperation. The results of the experiment suggest that extending the game in this way actually does increase cooperation significantly.

The Gilson and Mnookin article suggested that lawyers develop reputations and that the reputation for being cooperative problem solvers can be a valuable asset. They argue that "the relationship between opposing lawyers and their capacity to establish a credible reputation for cooperation have profound implications for dispute resolution." ${ }^{32}$ The experiment described in this article obviously tests only a small, but important piece of

${ }^{30}$ James Andreoni and John Miller, Rational Cooperation in the Finitely Repeated Prisoner's Dilemma: Experimental Evidence, 103 Econ J 570 (1993).

${ }^{31}$ We use their partner's treatment for comparison, where subjects play all 10 games with the same counterpart.

${ }^{32}$ Gilson and Mnookin, at 564 (cited in note 1). 
their much more complicated, and institutionally elaborate argument. Nevertheless, the results of our experiment do suggest that self-interested clients would frequently choose cooperative lawyers if they could be confident that either (1) the other side would do the same or, (2) if the other side did not, they could switch their representation. It also suggests that the existence of cooperative lawyers with recognizable reputations may well support more cooperative client behavior.

In conclusion, two important but obvious points bear emphasis. First, as Gilson and Mnookin themselves point out, the real world of litigation is much more complicated than their model. They suggest that not all litigation has a payoff structure consistent with a Prisoner's Dilemma game. Moreover, the assumptions of the prelitigation game (and the rules governing our experiment) are demanding: reputations are known in advance, and stable; a client can costlessly switch from a cooperative attorney to a gladiatorial one if the other side fails to choose a cooperative attorney; and no changes in attorneys are permitted once the litigation game begins. A similar point was also made by Russell Korobkin, who suggested that in the real world litigants may not know or understand the payoffs involved with their choice of lawyers. ${ }^{33}$

The realism or appropriateness of these (demanding) assumptions are not tested in the experiment presented in this article. Rather, the experiment provides a test of the implications of these assumptions. If all these conditions are met, is the outcome we observe the outcome we expect-more cooperation? The answer from this experiment is a conclusive yes.

The second point is equally obvious but also important. To the extent there are real-world institutions that facilitate and promote the efficiency of reputational markets, it would seem that cooperation might well be enhanced. These results pose an interesting question-well beyond the scope of this article-about what institutional arrangements might best support and promote the existence of reputational markets. Other sorts of research-empirical rather than experimental-might usefully explore the complex set of puzzles concerning how reputations are developed and are sustained, and how lawyers actually cooperate in the litigation process.

${ }^{33}$ Russell Korobkin, personal communication. 
This content downloaded from 130.91.116.52 on Mon, 27 Jun 2016 20:14:00 UT All use subject to http://about.jstor.org/terms 